rDNA. Muramatsu is busy trying to identify the active component(s) in fraction D but reckons that he may need $1 \mathrm{~kg}$ of $\mathrm{HeLa}$ cells for this purpose. (By contrast, a single Xenopus oocyte yields $10 \mathrm{ng}$ of a factor needed for transcription of 5S RNA genes by RNA polymerase III.)

Using a similar approach, S. Jacob of Hershey Medical Center (personal communication) has been able to separate to a high degree of purity transcription factors from rat mammary adenocarcinoma cells. When large quantities of cells, rather than isolated nuclei, are used as starting material, a complete transcriptionally active complex can be obtained. By dissecting out the components of this enzymefactor complex a characterization of at least some factors should be possible.

Why should there be a lack of sequence conservation in RNA polymerase I promoters and species-dependency of transcription factors? As argued by Grummt et al. ${ }^{16}$, since RNA polymerase I transcribes only a single type of transcription unit, fixation of mutation within promoters of multiple rRNA genes can take place at a much higher rate than in polymerase II and III promoters, which would require the co-evolution of many different kinds of gene. The divergence of
rDNA promoters seems to have been, and perhaps had to be, accompanied by appropriate modification of the enzyme and/or transcription factors. What led to the evolutionary selection of the divergence will continue to puzzle us for some time.
2. Mishima, Y. et al. Nucleic Acids Res, 9, 6773 (1981).
3. Verbeet, M. Ph. et al. Gene 23, 53 (1983).
4. Boseley, P.G. et al. Cell 17, 19 (1979).
5. Bach, R., Allet, B. \& Crippa, M. Nucleic Acids Res. 9, 5311 (1981).
6. McStay, B. \& Bird, A. Nucleic Acids Res. 11, 8167 (1983).
7. Financsek, I. et al. Proc. natn. Acad. Sci. U.S.A. 79, 3092 (1982).
8. Kohorn, B.D. \& Rae, P.M.M. Proc. natn. Acad. Sci. U.S.A. 80, 3265 (1983)
9 Grummt, I. Proc. natn. Acad. Sci. U.S.A. 79, 6908 (1982) 0. Yamamoto, O. et al. Proc. natn. Acad. Sci. U.S.A. 81 299 (1984).
11. Skinner, J.A., Ohrlein, A. \& Grummt, 1. Proc. natn. Acad. Sci. U.S.A. 81, 2137 (1984).
12. Learned, R.M. et al. Proc. natn. Acad. Sci. U.S.A. 80,3558 (1983)
13. Moss, T. Cell 30, 835 (1982)
14. Busby, S.J. \& Reeder, R.H. Cell 34, 989 (1983).
15. Reeder, R.H., Roan, J.G. \& Dunaway, M. Cell 35, 449 (1983).
16. Grummt, I., Roth, E. \& Paule, M.R. Nature 296, 173 (1982)
17. Mishima, Y. et al. Nucleic Acids Res. 10, 6659 (1982).
18. Saiga, H. et al. Nucleic Acids Res. 10, 4223 (1982).
18. Saiga, H. et al. Nucleic Acids Res. 10, 4223 (1982).
19. Hoshikawa, Y., lida, Y. \& Iwabuchi, M. Nucleic Acids Res. 11, 1725 (1983).
20. Blum, B. et al. Nucleic Acids Res. 11, 8519 (1983).

John Sommerville is in the Department of Zoology, Bute Buildings, The University, St Andrews, Fife KY16 9TS.

\title{
Ecology
}

\section{Oceanic noise and fish stocks}

\section{from Robert M. May}

IN recent years, many heavily exploited fish stocks have shown large fluctuations both in recruitment patterns and in overall abundance'. Such fluctuations cannot, however, be unambiguously attributed to the effects of harvesting, because there is evidence that many pelagic fish species have undergone large and rapid changes in abundance in the past. Major changes in the abundance of Pacific sardine or Atlantic herring, for example, appear to have occurred every 50-100 years for the past several centuries; these fluctuations have taken place abruptly, and do not appear to be accompanied by similarly rapid changes in the physical environment. Recently, Steele and Henderson ${ }^{2}$ have offered an explanation of this phenomenon that involves the interplay between a plausible model for the intrinsic dynamics of pelagic fish populations and the kind of environmental noise found in the oceans.

Most work in theoretical ecology that explores the effects of environmental noise upon population dynamics assumes the noise to be 'white' 3,4 . For white noise, the variability manifested when one point in time is compared with another is independent of the time interval separating the two points; the variance is constant as the time interval increases from very short to very long times. This corresponds to the variance (per unit frequency) of the
Fourier-transformed frequency spectrum of the environmental noise being the same for all frequencies. In analogy with visible light, such a colourless noise spectrum is thus called white. There is, moreover, evidence that white noise may be an appropriate assumption for some kinds of variability in terrestrial environments: reviews of data for atmospheric variability and for tree rings show spectra that are white (at least down to frequencies corresponding to 100 year intervals) ${ }^{5}$.

Steele and Henderson argue that environmental fluctuations in the sea typically are different from those on land, exhibiting 'red' noise spectra in which the variance systematically increases towards the low-frequency end. In particular, for environmental factors such as temperature or sea level, for which relatively long records are available, the variance scales roughly as (frequency) ${ }^{-n}$, with $n$ between 1.5 and 2; that is, the variance increases steadily as the time interval increases from days to decades ${ }^{6-8}$. Although Steele and Henderson rely mainly on empirical evidence, it is worth noting that simple stochastic models of the physical interactions between atmosphere and ocean also indicate that white noise in the atmosphere changes to red noise in the ocean ${ }^{9}$.

Steele and Henderson describe the population dynamics of their fish stocks by a model with the following features: in the absence of predators, the population is regulated at relatively high density by the availability of resources; at high predation levels, the population is regulated at relatively low densities by predation; and there can be an intermediate regime in which the population has two alternative stable states (one essentially resourcelimited, the other essentially predatorlimited). Such models, with the possibility for two alternative equilibrium states, have already been discussed in relation to insect pests ${ }^{10}$, grazing herbivores ${ }^{11}$, pathogens and other situations ${ }^{12}$. The new twist imparted by Steele and Henderson is the insertion of environmental stochasticity with a red-noise spectrum into the system (specifically, into the predation term). The parameters in the model are estimated as those appropriate to pelagic fish, and the noise spectrum scales as (frequency) ${ }^{-2}$, as above. Numerical studies with the model show the fish population undergoing moderate fluctuations about a steady high level, or about a steady low level, with abrupt transitions from one level to the other taking place every 50 years or so.

These observations could have important implications. In Steele and Henderson's words", "In the context of fisheries management, there is usually a tacit assumption that we are operating within periods where stocks are persistent, albeit with large year-to-year fluctuations in recruitment. The data ... suggest that the period 1920 to 1960 , when much of fishery theory and practice was developed, was such an interval. More recently, large concurrent changes in stocks cast doubt on this assumption and raise critical management questions about the relative significance of environmental and fishery factors". Of course, the model explored by Steele and Henderson is a very simple one, and a good deal remains to be done before we accept that red noise in the ocean environment has tipped marine ecosystems from one state into another, largely independently of fishing. Nevertheless, as this work goes forward, it could well have relevance beyond fisheries. For example, insofar as marine environments differ from terrestrial ones in having predominantly red rather than white noise spectra, what would this imply for community structure and function?

1. Lawton, J.H. \& May R.M. Nature 309,744 (1984).

2. Stecle J.H. \& Henderson E.W. Science 224, 985 (1984).

3. May, R.M. Stability and Complexity in Model Ecosystems (Princeton University Press, 1974)

4. Turelli, M. Theor. Pop. Biol. 12, 140 (1977).

5. Understanding Climatic Change: A Program for Action (National Academy of Sciences, Washington DC, 1975). 6. Munk, W.H. \& Cartwright, D.E. Phil Trans. R. Soc. 259, (1966)

7. Wunsch, C. Evolution of Physical Oceanography (MIT Press, Cambridge, 1981).

8. Hays, J.D. et al Science 194, 1121 (1976)

8. Hays, J.D. et al. Science 194, 112
9. Lemke, P. Tellus 29, 385 (1977).

10. Ludwig, D., Jones, D.D. \& Holling, C.S. J. A nim. Ecol. 47, 315 (1978).

1. Noy-Meir, I. J. Ecol. 63, 459 (1975).

12. May, R.M. Nature 269, 471 (1977).

Robert M. May is Class of 1877 Professor of Zoology at Princeton University, New Jersey 08544 . 